\title{
Oral Malignant Melanoma: A Case Report
}

\author{
Suman Sen ${ }^{1}$, Sheuli Sen ${ }^{2}$, M. Geetha Kumari ${ }^{3}$, Sufia Khan ${ }^{3}$, \\ Subhasini Singh ${ }^{3}$
}

${ }^{1}$ Department of Oral Medicine and Radiology, Haldia Institute of Dental Sciences and Research, Haldia, West Bengal, India;

${ }^{2}$ Department of Pediatric Nursing, Sumandeep Nursing College, Sumandeep University, Vadodara, Gujarat, India;

${ }^{3}$ Department of Oral Pathology and Microbiology, Awadh Dental College and Hospital, Jamshedpur, Jharkhand, India

Received June 30, 2020; Accepted August 3, 2021.

Key words: Malignant melanoma - Palate - Pigmentation - Melanocytes

Abstract: Melanoma is a malignant neoplasm of the epidermal melanocytes. Awareness and early recognition of pigmented lesion inside oral cavity helps in initial diagnosis and further investigation and treatment. Oral malignant melanoma is a rare aggressive neoplasm commonly seen among middle age. The diagnosis of melanoma initiates from the pre-existing pigmented lesions. The poor prognosis of oral melanomas requires that pigmented lesions of undetermined origin be routinely biopsied. A case of malignant melanoma of hard palate with its clinical, radiological and histopathological presentation along with brief review is presented. Prognosis of these lesion is poor with survival rate of 5 years.

Mailing Address: Dr. Suman Sen, A-4/6, Purbasha, 160 manicktala main road, Kolkata, West Bengal, India; e-mail: sumansen20@yahoo.co.in 


\section{Introduction}

Oral malignant melanomas are extremely rare lesions and occur commonly in the maxillary gingival and palatal region. Malignant melanoma is the third most common skin malignancy, yet it comprises of only 3 to $5 \%$ of all cutaneous malignancies (Boulaadas et al., 2007). Malignant melanomas of the oral cavity are extremely rare accounting for $0.2-8 \%$ of all malignant melanomas (Ebenezer, 2006; Guevara-Canales et al., 2012). Lesions are mainly very aggressive in nature but mostly go unnoticed as these lesions are clinically asymptomatic in the early stages and noted as hyperpigmented patch. Melanoma is a malignant tumour comprise of melanocytes in which cells are derived from the neural crest that constitute the melanin pigment in the basal and suprabasal layers of the epithelium (Ashok et al., 2020). Although most melanomas arise in the skin, they may also arise from mucosal surfaces (Deyhimi et al., 2017).

\section{Case report}

A 59-year-old male patient came to the department of oral medicine and radiology with the chief complaint of blackish pigmented area over the palate. Patient does not have symptom like pain or burning sensation, his main concern was aesthetic. Initially he noticed small patches of dark black pigmented area 6 months ago which increases to present size. There was a rapid spread of the hyperpigmented lesions which covered the entire palatal region. There was no familial history of carcinomas.

On clinical examination, the lesion was dark blackish to brownish in colour with irregular borders clearly demarcated from the adjacent area. Lesion covering left to centre part of hard palate extending from middle third to junction of hard and

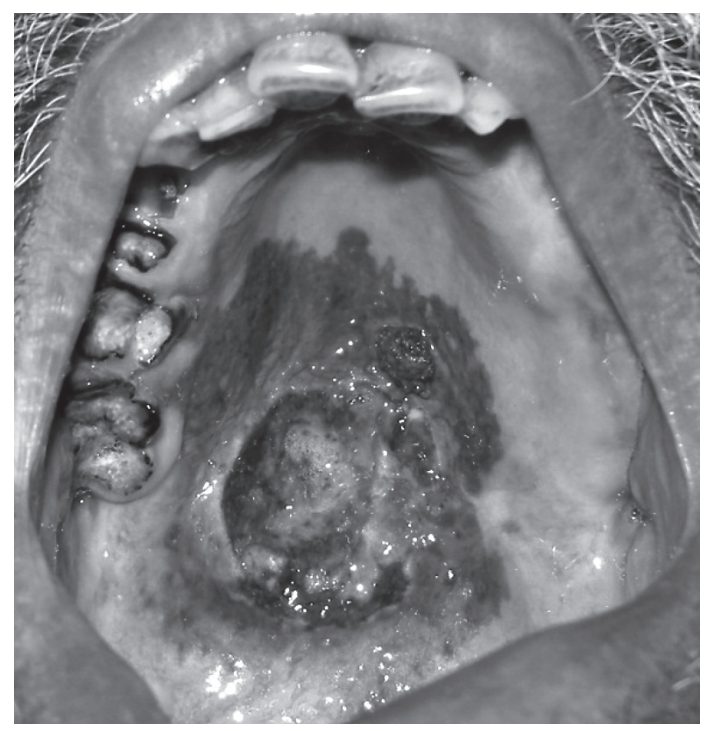

Figure 1 - A well-defined blackish brownish irregular shaped lesion with a nodular elevation in middle seen over hard palate. 


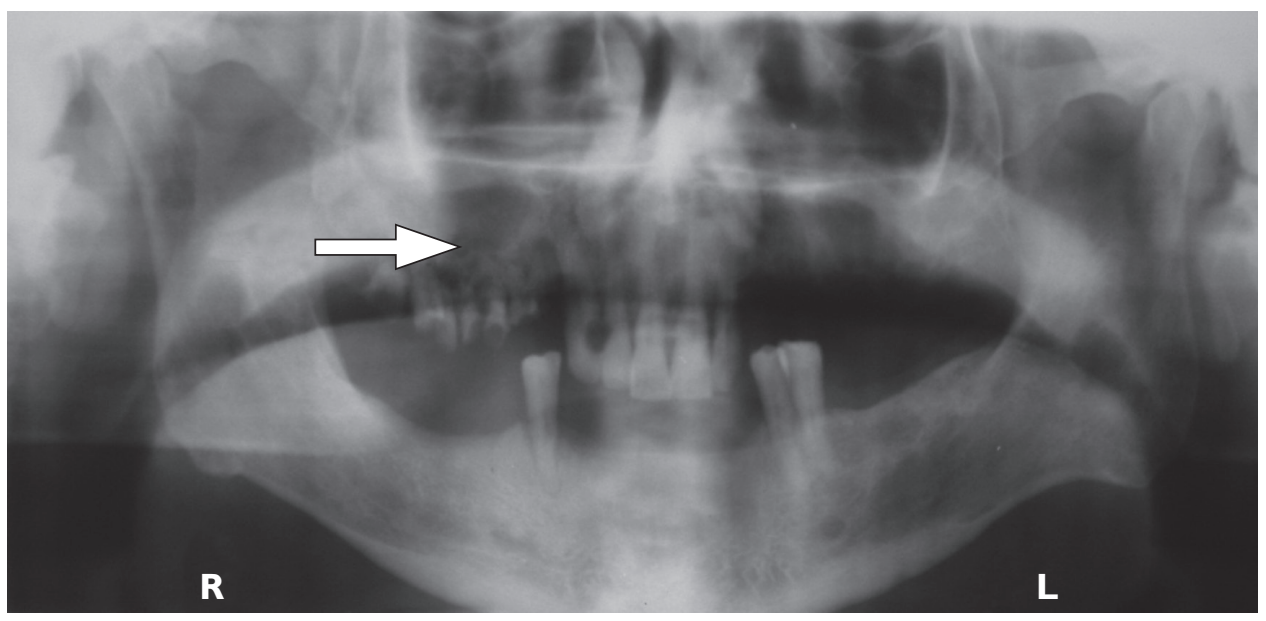

Figure 2 - Orthopantomograph showing a well-defined radiolucent oval right side of palate.

soft palate. Irregular in shape with ragged borders measuring around $3 \times 3.5 \mathrm{~cm}$. The surface appeared wrinkled, granular with a proliferative elevated area seen in midline palate (Figure 1). On palpation, the lesion was fibrotic non-scrapable and non-tender. The regional lymphnodes were not palpable.

Orthopantomograph (OPG) revels there is a well-defined radiolucency in right middle part of hard palate suggestive of bone erosion appearing as palatal loss (Figure 2). Under local anaesthesia a biopsy sample collected from proliferative region of hard palate.

In histopathological examination revels the given sift tissue $\mathrm{H}$ and $\mathrm{E}$ (haematoxylin and eosin) stained section shows parakeratininzed stratified squamous epithelium

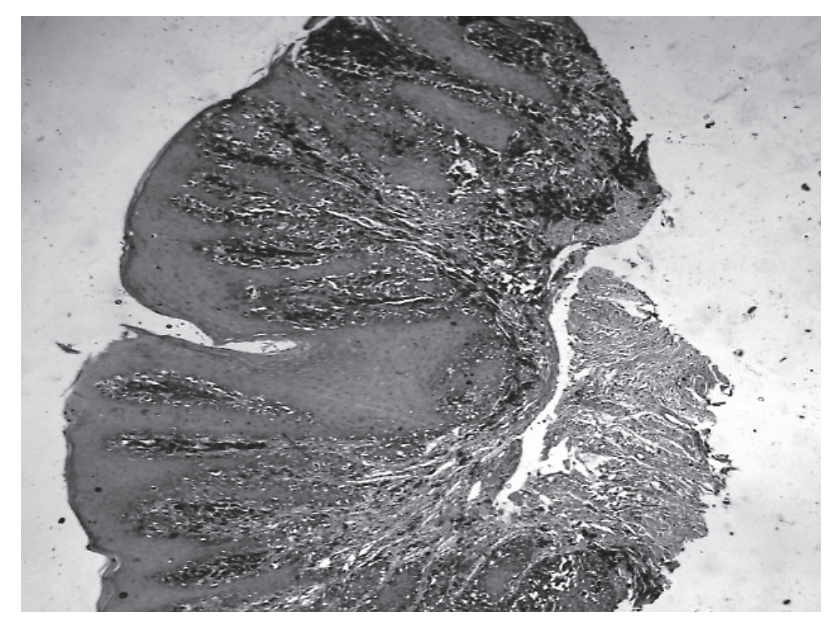

Figure 3 - Malignant melanocytes in epithelium and in stroma (under $4 \times$ microscope).

Sen S.; Sen S.; Kumari M. G.; Khan S.; Singh S. 


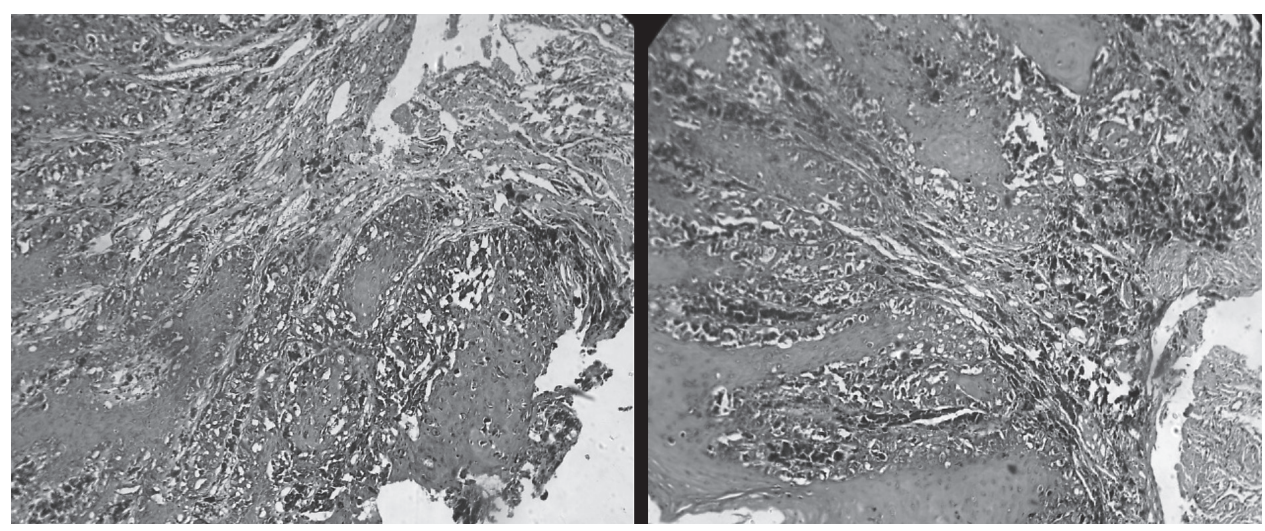

Figure 4 - Malignant melanocytes with dysplastic features in the epithelium as well as in stroma (under 10x microscope).

with dark brown coloured cells resembling melanocytes and are present throughout the epithelium and are arranged in nests and islands. Melanocytes are large and shows cellular pleomorphism, anisonucleosis and anisocytosis. Basal cell layer degeneration is seen with melanocytes invading into the connective tissue stroma. In the connective tissue, melanocytes are forming islands, and some are singly present. Stroma is dense with collagen fibres, fibroblasts and fibrocytes. Dilated blood vessels have also been reported with extravasated red blood cells. Focal areas of chronic inflammatory chiefly lymphocytes are also seen. Pigmentation is also noted in various places (Figures 3 and 4). Based on clinical, radiological and histopathological presentation its final diagnosed as malignant melanoma. Chest $\mathrm{X}$-ray did not show any metastasis to lungs. A PET (position emission tomography) scan was performed, which did not show any distant metastasis. The patient was referred to oral and maxillofacial surgeon for excision of the lesion for further treatment and the prognosis of the lesion was explained. The patient wanted treatment in a different city and was referred for further management.

\section{Discussion}

Melanin is an endogenous non hematogenous pigment. It is initially formed by melanocytes in the basal layer of the epithelium and is transferred to adjacent keratinocytes via membrane-bound organelles called melanosomes. Benign lesions like common acquired nevus, congenital nevus, dysplastic nevus and cellular blue nevus are said to undergo a malignant transformation to melanoma. Mucosal melanoma was first described by Weber in 1895. Cigarette smoking, denture irritation and alcohol consumption are some of the suggested risk factors ( $\mathrm{Wu}$ et al., 2016). Tobacco and formaldehyde exposures have also been suggested as causative agents for intraoral melanomas. Risk factors for melanoma include 
Caucasian ancestry, fair skin, light hair and a history of intense sun exposure, and moles that are unusually numerous, large, irregular (Feller et al., 2017). Mostly it is seen between the ages of 40 to 70 years (Smith et al., 2016). Malignant melanoma is commonly seen in men compared to women (Singh et al., 2019). Most common site inside oral cavity is the palate followed by maxillary gingiva with an incidence of $80 \%$ and $91.4 \%$, respectively (Lamichhane et al., 2015). It tends to rapidly spread to other parts of the body causing death.

Criteria for clinical diagnosis of melanoma (rule of $A B C D E$ )

- Asymmetry - is when one-half of the lesion does not match the other half of lesion;

- Border irregularity - is when the edges are, notched, ragged or blurred;

- Colour irregularity - various coloured pigmentation is seen ranging from black, brown, tan, red, blue and white;

- Diameter - more than $6 \mathrm{~mm}$;

- Elevation from the adjacent surface.

Melanoma can be categorised as different types as superficial spreading, nodular melanoma, lentigo maligna melanoma, acrallentiginous melanoma and mucosal lentiginous melanoma. Among these acrallentiginous and mucosal lentiginous melanoma commonly occur in the oral cavity. Hard palate is the most commonly involved site where it presents as a brown to black macule with irregular borders.

Surgery, chemotherapy, radiotherapy, and immunotherapy are preferred treatment. It has been shown that recent surgical excision followed by immuno-chemotherapy has reduced or prevented the recurrence of the lesion. The prognosis of oral melanoma is poor with a five-year survival of $15-38 \%$ of cases (Aloua et al., 2021). Cases where there is metastasis has already involved then the disease is considered as classically incurable, surgery, radiotherapy and chemotherapy could be considered under the palliative care.

\section{Conclusion}

A small, pigmented lesion inside oral cavity is very much misleading as it does not have any symptoms unless it became big and noted by the patient. Its early proper diagnosis can be life saving for the patient as it can be very aggressive and a invade to adjacent area.

\section{References}

Aloua, R., Kaouani, A., Kerdoud, O., Salissou, I., Slimani, F. (2021) Melanoma of the oral cavity: A silent killer. Ann. Med. Surg. (Lond.) 62, 182-185.

Ashok, S., Damera, S., Ganesh, S., Karri, R. (2020) Oral malignant melanoma. J. Oral Maxillofac. Pathol. 24, S82-S85 (Suppl. 1).

Boulaadas, M., Benazzou, S., Mourtada, F., Sefiani, S., Nazih, N., Essakalli, L., Kzadri, M. (2007) Primary oral malignant melanoma. J. Craniofac. Surg. 18(5), 1059-1061. 
Deyhimi, P., Razavi, S. M., Shahnaseri, S., Khalesi, S., Homayoni, S., Tavakoli, P. (2017) Rare and extensive malignant melanoma of the oral cavity: report of two cases. J. Dent. (Shiraz) 18(3), 227-233.

Ebenezer, J. (2006) Malignant melanoma of the oral cavity. Indian J. Dent. Res. 17(2), 94-96.

Feller, L., Khammissa, R., Lemmer, J. (2017) A review of the aetiopathogenesis and clinical and histopathological features of oral mucosal melanoma. ScientificWorldjournal 2017, 9189812.

Guevara-Canales, J. O., Gutiérrez-Morales, M. M., Sacsaquispe-Contreras, S. J., Sánchez-Lihón, J., MoralesVadillo, R. (2012) Malignant melanoma of the oral cavity. Review of the literature and experience in a Peruvian Population. Med. Oral Patol. Oral Cir. Bucal 17(2), e206-e211.

Lamichhane, N. S., An, J., Liu, Q., Zhang, W. (2015) Primary malignant mucosal melanoma of the upper lip: a case report and review of the literature. BMC Res. Notes 8, 499.

Singh, D., Pandey, P., Singh, M. K., Kudva, S. (2019) Prevalence of malignant melanoma in anatomical sites of the oral cavity: a meta-analysis. J. Oral Maxillofac. Pathol. 23(1), 129-135.

Smith, M. H., Bhattacharyya, I., Cohen, D. M., Islam, N. M., Fitzpatrick, S. G., Montague, L. J., Damm, D. D., Fowler, C. B. (2016) Melanoma of the oral cavity: An analysis of 46 new cases with emphasis on clinical and histopathologic characteristics. Head Neck Pathol. 10(3), 298-305.

Wu, W., Liu, H., Song, F., Chen, L. S., Kraft, P., Wei, Q., Han, J. (2016) Associations between smoking behavior-related alleles and the risk of melanoma. Oncotarget 7(30), 47366-47375. 